\title{
Blueprint of CBPWM for qZSI using SIMULINK and EZDSP F28335
}

\author{
Yew Wei Sia ${ }^{1}$,Kah Haw Law ${ }^{1}$, and Sy Yi Sim ${ }^{2}$ \\ ${ }^{1}$ Department of Electrical and Computer Engineering, Faculty of Engineering and Science, Curtin University \\ Malaysia, 98009, Miri, Sarawak, Malaysia \\ siayewwei@ postgrad.curtin.edu.my, lawkahhaw@curtin.edu.my \\ ${ }^{2}$ Department of Electrical Engineering Technology, Faculty of Engineering Technology, UniversitiTun Hussein \\ Onn, 84600, Muar, Johor, Malaysia \\ sysim@uthm.edu.my
}

\begin{abstract}
The cost efficient single-phase quasi z-source inverter (qZSI) is constructed in single stage topology. Among the traditional two stage power converter/inverter topologies, qZSI performs buck/boost $\mathrm{DC}$ to $\mathrm{AC}$ inversion without requiring one extra switching device for generating/outputting three-level AC voltage. However, it is crucial for qZSI to switch at very high switching frequency in order to charge and discharge the passive components (i.e., inductors and capacitors) in the quasi z-source network (qZSN) for driving the load and boosting the DC-link voltage, respectively. Therefore, this paper presents the new blueprint of Carrier-Based Pulse-Width-Modulation (CB-PWM) technique associated to hardware implementation for single-phase qZSI. The proposed method is built with Enhanced Pulse Width Modulator (EPWM) SIMULINK block in MATLAB/SIMULINK to program the EZDSP F28335 microcontroller. It allows the digital signal processor (DSP) controller to output pulse trains with great accuracy switching at high switching frequency. Moreover, the proposed method can reduce the switching power loss and improve the system inversion efficiency based on sawtooth carrier waveform operated in Count-up (CU) mode. The experiment is also carried out to validate the aforementioned advantages in this work.
\end{abstract}

Key words :Carrier-Based Pulse-Width-Modulation (CB-PWM), Enhanced Pulse Width Modulator (EPWM), Quasi Z-Source Inverter (qZSI), Simple Boost Control (SBC).

\section{INTRODUCTION}

In recent years, it is becoming evident that the renewable energy, particularly photovoltaic (PV), is more sustainable when compared to fossil fuels [1]-[2]. In addition, the progressive development of qZSI topology has been extensively employed to Solar PV system[3]-[4]. The reason behind choosing the aforementioned topology over the traditional two stage power inverters is that it can buck or boost DC supply and then invert it to AC voltage via a single conversion stage[5]-[9]. It also has several advantages such as low construction and material expenditure, smaller footprint, as well as high conversion efficiency[10]-[13].

The qZSI is repeatedly switching between two states (i.e., shoot-through and non-shoot-through) when operating in continuous conduction mode (CCM) in regardless of driving with any modulation technique[14]-[15]. Generally, there are three classic CB-PWM techniques which designed for qZSI. Those are known as Simple Boost Control (SBC), Maximum Boost Control, and Maximum Constant Boost Control (MCBC). Among the techniques, $\mathrm{MCBC}$ is preferable because of the high voltage gain attainment[16].

There have been several researches investigating different modulation techniques for qZSI. For instance, Liu [11], [17]anticipated the modified Space Vector (SV) PWM technique which included shoot-through state as well as non-shoot-through state formed by six active voltage vectors and two conventional zero vectors. The benefits offered by the aforementioned technique include low total harmonic distortion (THD) [18], high DC-link voltage utilization, and simple digital realization. A control scheme based phase-shift-CB-PWM (PS-CB-PWM) was proposed for multilevel qZSI with separately isolated DC sources to achieve power balancing across different qZSI modules [19]-[20]. The aforementioned multilevel inverter topology was switching at $10 \mathrm{kHz}$, which is considering low for the conventional qZSI to operate in CCM.

Knowing that high accuracy and high switching frequency of gate signals are essential for qZSI to minimize the right half plane zero and achieve lower current ripple with smaller size of the inductor, no work has unveiled the implementation of modulation technique using EZDSP F28335 microcontroller and MATLAB/SIMULINK[13], [21]-[22]. Therefore, this paper contributes to the unique design of CB-PWM technique for single-phase qZSI which implemented using 
MATLAB/SIMULINK and EZDSP F28335 programming for single-phase qZSI. The proposed method can ensure the EZDSP F28335 microcontroller to output accurate pulse trains with high switching frequency to boost up the DC voltage source and then invert it into $\mathrm{AC}$ voltage to drive the load. Researchers can refer to[23] to find out more about the introduction and tutorial on the configuration of EZDSP F28335 microcontroller using MATLAB/SIMULINK. The aforementioned combo has been proven to be a cheaper controller implementation option that provides excellent convergence as well as real-time feedback control in simulation modelling as well as code generation and debugging for power electronic system.

The rest of the paper's content covered: Introduction of the working principle of qZSI and its mathematical derivation for theoretical analysis, demonstration of MATLAB/SIMULINK model implementation to program the EZDSP F28335 microcontroller followed by simulation and experimental results analysis. The paper ended with conclusion.

\section{WORKING PRINCIPLE OF QUASI Z-SOURCE INVERTER}

The conventional qZSI circuit diagram shown in Figure 1 has two different operating states (i.e., shoot-through state and non-shoot-through state)[14], [24].

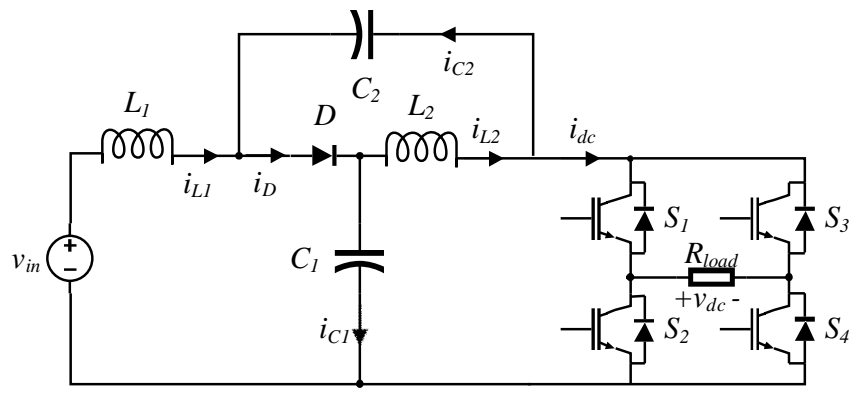

Figure 1: Conventional qZSI topology

In shoot-through state, the series-connected switching elements in the same bridge leg (i.e., $S_{1} S_{2}$ or $S_{3} S_{4}$ ) of H-bridge inverter are conducted to reverse bias the diode allowing input energy to be stored via the inductors (i.e., $L_{1}$ and $L_{2}$ ). In the event whereby the qZSI is in non-shoot-through state, the series-connected switching elements (i.e., $S_{1} S_{4}$ or $S_{2} S_{3}$ ) are conducted to discharge the aforementioned stored energy (i.e., $I_{L 1}$ and $I_{L 2}$ ) via the diode to simultaneously charge the capacitors (i.e., $C_{1}$ and $C_{2}$ ) and drive the load.

To analyze the operation of qZSI topology, the state space equations (i.e., in matrix form) of shoot-through state $\left(D_{s h}\right)$ and non-shoot-through state $\left(1-D_{s h}\right)$ relating to the system parameters found in Figure 1 are derived in (1) and (2), respectively [15].

Next, to attain its state space average dynamic equation, the steady-state shoot-through duty ratio $D_{s h}$ and $\left(1-D_{s h}\right)$ are substituted into (1) and (2), respectively, given in (3).By assuming steady-state operation and equating the left side parameters of (3) to zero, the equations of DC input voltage $V_{i n}$, DC-link voltage $\underline{V}_{d \underline{c}}$, DC capacitor voltages $\left(V_{C 1}\right.$ and $\left.V_{C 2}\right)$, boost factor $\beta$, modulation index $M_{i}$, and voltage gain $G$ of qZSI are realized and derived in (4)-(9), respectively[15].

$$
\begin{aligned}
& {\left[\begin{array}{cccc}
L_{1} & 0 & 0 & 0 \\
0 & L_{2} & 0 & 0 \\
0 & 0 & C_{1} & 0 \\
0 & 0 & 0 & C_{2}
\end{array}\right]\left[\begin{array}{l}
i_{L 1}^{\cdot} \\
l_{L 2} \\
v_{C 1} \\
v_{C 2}^{\cdot}
\end{array}\right] } \\
&=\left[\begin{array}{cccc}
0 & 0 & 0 & 1 \\
0 & 0 & 1 & 0 \\
0 & -1 & 0 & 0 \\
-1 & 0 & 0 & 0
\end{array}\right]\left[\begin{array}{l}
i_{L 1} \\
i_{L 2} \\
v_{C 1} \\
v_{C 2}
\end{array}\right] \\
&+\left[\begin{array}{ll}
1 & 0 \\
0 & 0 \\
0 & 0 \\
0 & 0
\end{array}\right]\left[\begin{array}{l}
v_{i n} \\
i_{d c}
\end{array}\right]
\end{aligned}
$$

$$
\begin{aligned}
& {\left[\begin{array}{cccc}
L_{1} & 0 & 0 & 0 \\
0 & L_{2} & 0 & 0 \\
0 & 0 & C_{1} & 0 \\
0 & 0 & 0 & C_{2}
\end{array}\right]\left[\begin{array}{l}
i_{L 1}^{\cdot} \\
l_{L 2} \\
v_{C 1}^{\cdot} \\
v_{C 2}^{+}
\end{array}\right] } \\
&=\left[\begin{array}{cccc}
0 & 0 & -1 & 0 \\
0 & 0 & 0 & -1 \\
1 & 0 & 0 & 0 \\
0 & 1 & 0 & 0
\end{array}\right]\left[\begin{array}{l}
i_{L 1} \\
i_{L 2} \\
v_{C 1} \\
v_{C 2}
\end{array}\right] \\
&+\left[\begin{array}{cc}
1 & 0 \\
0 & 0 \\
0 & -1 \\
0 & -1
\end{array}\right]\left[\begin{array}{l}
v_{i n} \\
i_{d c}
\end{array}\right]
\end{aligned}
$$$$
\left[\begin{array}{cccc}
L_{1} & 0 & 0 & 0 \\
0 & L_{2} & 0 & 0 \\
0 & 0 & C_{1} & 0 \\
0 & 0 & 0 & C_{2}
\end{array}\right]\left[\begin{array}{l}
l_{L 1}^{\cdot} \\
l_{L 2}^{\cdot} \\
v_{C 1}^{\cdot} \\
v_{C 2}^{\cdot}
\end{array}\right]
$$$$
=\left[\begin{array}{cccc}
0 & 0 & D_{s h}-1 & D_{s h} \\
0 & 0 & D_{s h} & D_{s h}-1 \\
1-D_{s h} & -D_{s h} & 0 & 0 \\
-D_{s h} & 1-D_{s h} & 0 & 0
\end{array}\right]\left[\begin{array}{c}
i_{L 1} \\
i_{L 2} \\
v_{C 1} \\
v_{C 2}
\end{array}\right]
$$$$
+\left[\begin{array}{cc}
1 & 0 \\
0 & 0 \\
0 & D_{s h}-1 \\
0 & D_{s h}-1
\end{array}\right]\left[\begin{array}{l}
v_{i n} \\
i_{d c}
\end{array}\right]
$$$$
V_{\text {in }}=V_{C 2}-V_{C 1}
$$$$
V_{d c}=V_{C 1}+V_{C 2}
$$$$
V_{C 1}=\frac{1-D_{s h}}{1-2 D_{s h}} V_{i n} V_{C 2}=\frac{D_{s h}}{1-2 D_{s h}} V_{\text {in }}
$$

$\beta=\frac{V_{d c}}{V_{\text {in }}}=\frac{1}{1-2 D_{s h}}=\frac{1}{2 M_{i}-1}$ 
Yew Wei Sia et al., International Journal of Emerging Trends in Engineering Research, 8(1.2), 2020, 83- 89

$M_{i}=\frac{B+1}{2 B}=1-D_{s h}$

$G=\frac{\beta+1}{2}=\frac{M_{i}}{2 M_{i}-1}$

From (6) or (7), the shoot-through duty ratio $D_{s h}$ must be in between the range of $0 \leq D_{s h}<0.5$ to ensure DC-link voltage $V_{d c}$ remains in finite range.

\section{MATLAB SIMULATION AND EXPERIMENTS}

\subsection{Simulation Modelling and Results}

The proposed CB-PWM technique based on SBC to generate the pulse trains of $S_{1}, S_{2}, S_{3}$ and $S_{4}$ for single-phase qZSI is shown in Figure 2.

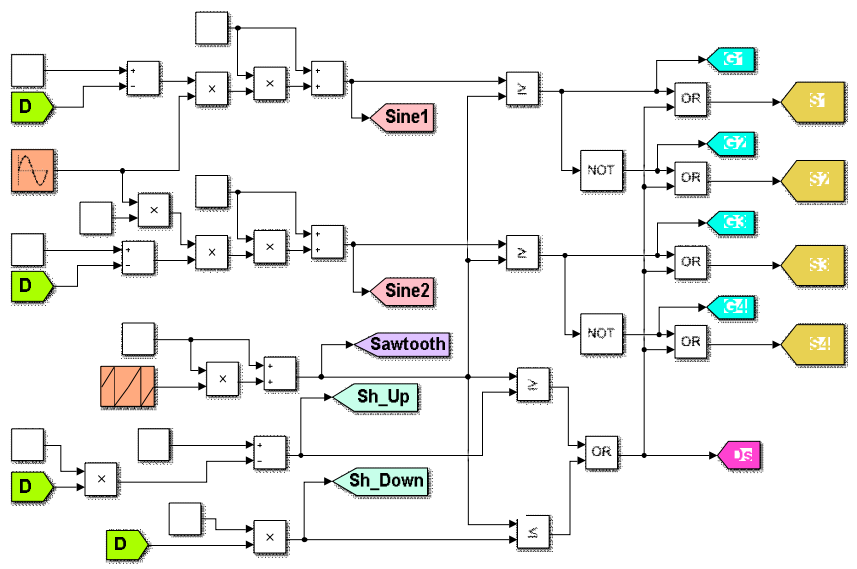

Figure 2: MATLAB/SIMULINK model of CB-PWM technique based on SBC for single-phase qZSI simulation

From Figure 2, the MATLAB/SIMULINK model is constructed with various blocks. Typically, the positive (i.e., from "Sine1" block) and negative (i.e., from "Sine2" block) sinusoidal waveforms where each amplitude is set by the modulation index $M_{i}$, the sawtooth signals (i.e., from "Sawtooth Generator" block) based on CU mode as well as the upper $\left(V_{u}{ }^{*}\right.$ from "Sh_Up" block) and lower $\left(V_{n}{ }^{*}\right.$ from "Sh_Down" block) shoot-through reference signals.

The aforementioned signals were fed to and compared with relational operator blocks and the visual representation of those are shown in Figure 3(a). Figure 3(b) to 3(k) present the shoot-through pulse trains of $V_{u}$ and $V_{n}$ (see Figure 3(b) and Figure 3(c), respectively), the non-shoot-through pulse trains of $G_{1}, G_{2}, G_{3}$, and $G_{4}$ (see Figure 3(d), Figure 3(e), Figure 3(f), and Figure 3(g), respectively), and the switching pulse trains of $S_{1}, S_{2}, S_{3}$, and $S_{4}$ ((see Figure 3(h), Figure 3(i), Figure 3(j), and Figure $3(\mathrm{k})$, respectively) which generated via the proposed modulation method.

The summary of the rules for the generation of pulse trains were tabulated in Table 1 .

\subsection{Experimental Setup and Results}

The design of the proposed CB-PWM technique for experimental work is constructed according to the computational simulation shown in Figure 2.

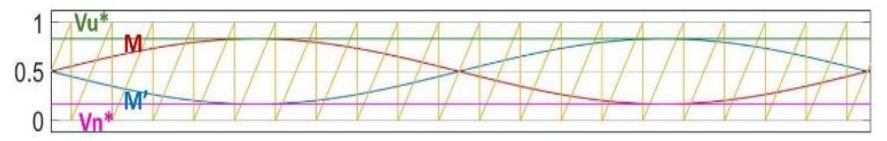

(a)

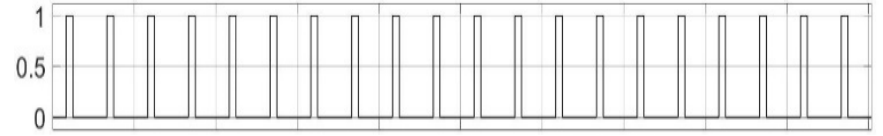

(b)

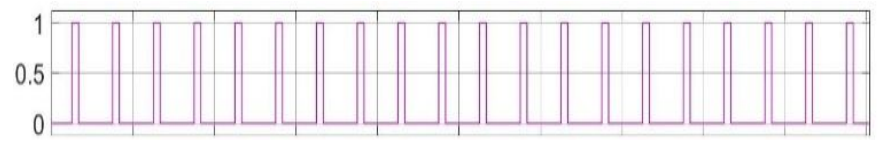

(c)

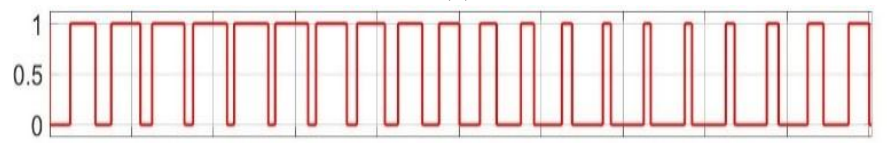

(d)

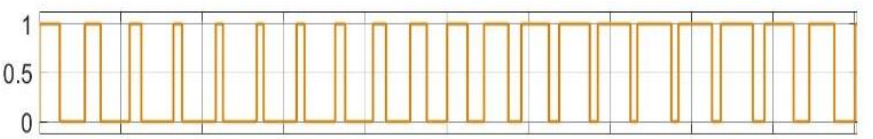

(e)

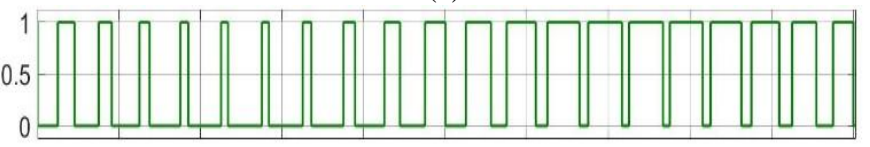

(f)

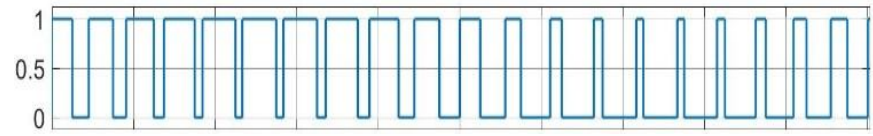

(g)

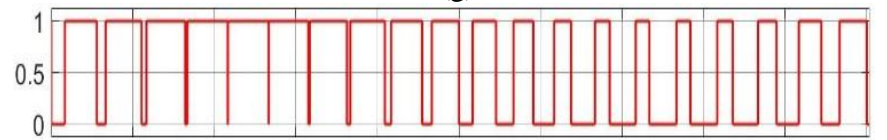

(h)

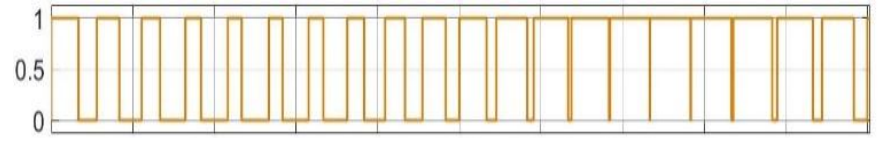

(i)

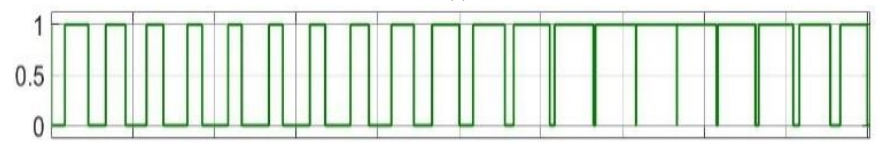

(j)

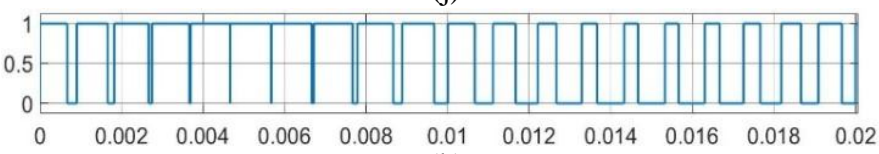

(k)

Figure 3. Simulation results of (a) CB-PWM based on CU mode carrier, the shoot-through pulse trains of (b) $V_{u}$ and (c) $V_{n}$, the non-shoot-through pulse trains of (d) $G_{1}$, (e) $G_{2}$, (f) $G_{3}$, and (g) $G_{4}$, and the switching pulse trains of (h) $S_{1}$, (i) $S_{2}$, (j) $S_{3}$, and (k) $S_{4}$. 
In this case, the proposed CB-PWM technique based on SBC to generate the non-shoot-through (i.e., $G_{1}, G_{2}, G_{3}$, and $G_{4}$ ) and the shoot-through (i.e., $V_{u}$ and $V_{n}$ ) pulse trains using MATLAB/SIMULINK model and EZDSP F28335 programming is shown in Figure 4.

Table 1: Pulse trains generation rules

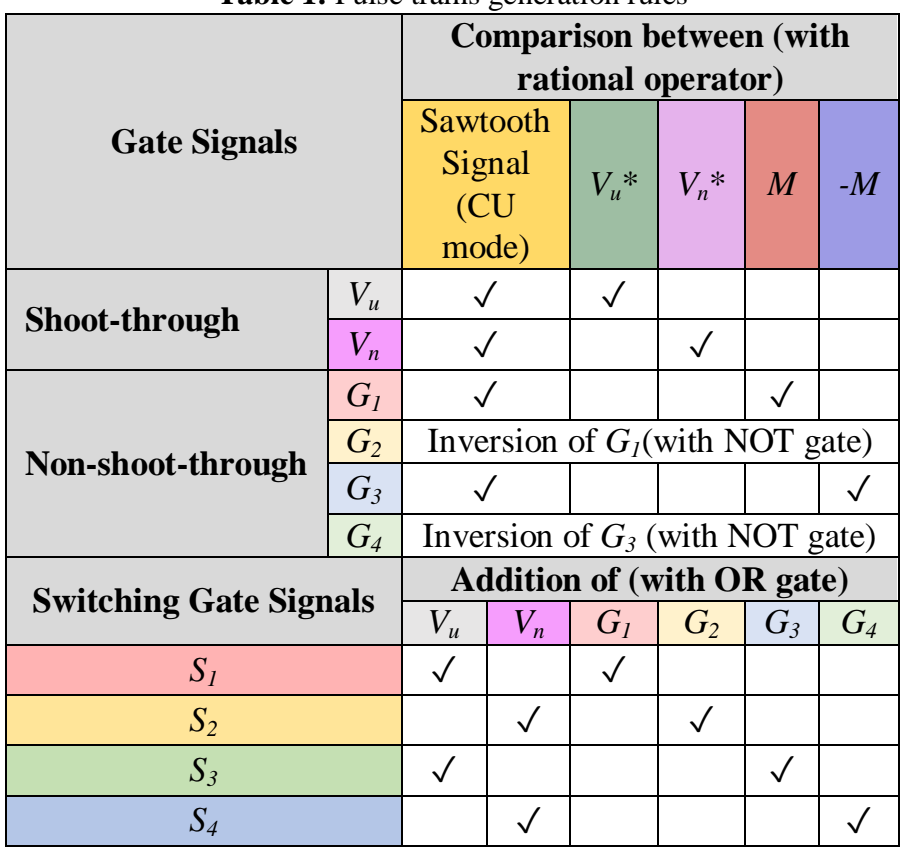

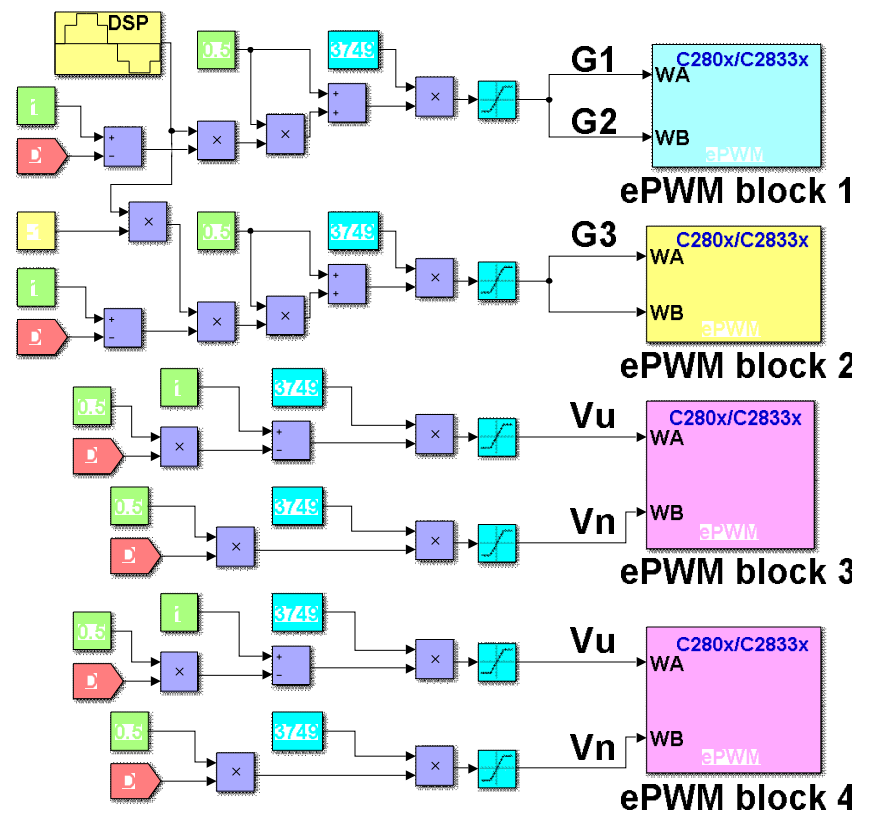

Figure 4: MATLAB/SIMULINK model of CB-PWM technique based on SBC for EZDSP F28335 programming on single-phase qZSI experiment

To obtain the final switching pulse trains (i.e., $S_{1}, S_{2}, S_{3}$ and $S_{4}$ ), the aforementioned signals are summed via OR gate (see. Figure 6) for single-phase qZSI as derived below:

$S_{1}=G_{1}+V_{u}(3 A)$

$$
\begin{aligned}
& S_{2}=G_{2}+V_{n}(3 B) \\
& S_{3}=G_{3}+V_{u}(4 A) \\
& S_{4}=G_{4}+V_{n}(4 B)
\end{aligned}
$$

From Figure 4, it is noted that the EPWM SIMULINK blocks are being utilized rather than choosing the General Purpose I/O (GPIO) blocks. This is because the aforementioned option allows the EZDSP F28335 microcontroller to output very accurate pulse trains with high switching frequency, which is crucial for qZSI to conduct in both shoot-through state and non-shoot-through state repetitively allowing the passive components in qZSN to be discharged and charged for boosting and driving purposes, respectively.

The experimental setup for the single-phase qZSI with EZDSP F28335 microcontroller is depicted in Figure 5 and its block diagram is shown in Figure 6.

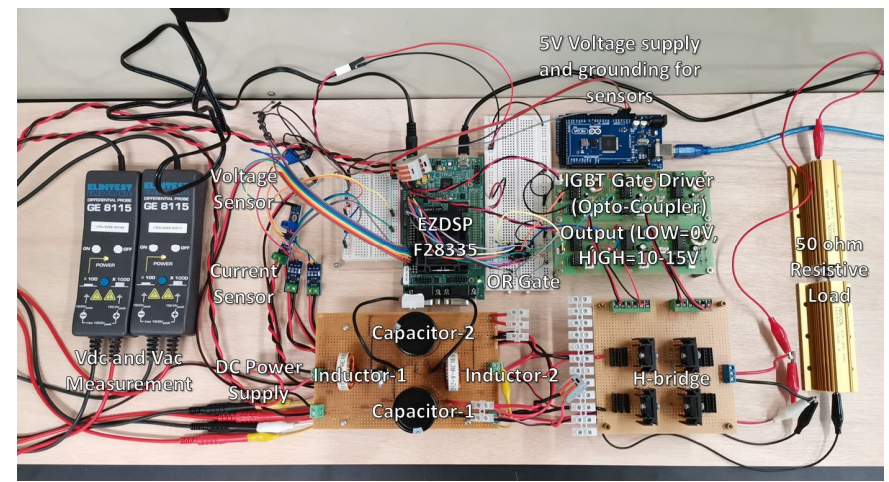

Figure 5: Experimental setup for single-phase qZSI with EZDSP F28335 microcontroller

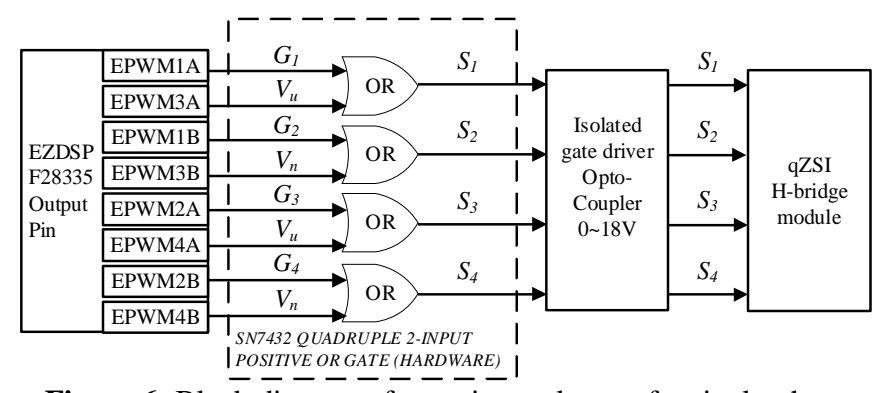

Figure 6: Block diagram of experimental setup for single-phase qZSI with EZDSP F28335 microcontroller

The system parameters of the experiment are tabulated in Table 2.

Table 2: System Parameters

\begin{tabular}{|l|c|}
\hline System specifications & Value \\
\hline DC input voltage, $V_{\text {in }}$ & $6 \mathrm{~V}$ \\
\hline Inductance of of Quasi Z-Source Inverter, $L_{1}$ and $L_{2}$ & $100 \mu \mathrm{H}$ \\
\hline Capacitance of Quasi Z-Source Inverter, $C_{1}$ and $C_{2}$ & $1000 \mu \mathrm{F}$ \\
\hline Resistance of the load in output, $R_{\text {load }}$ & $50 \Omega$ \\
\hline Switching frequency, $f_{\mathrm{sw}}$ & $40 \mathrm{kHz}$ \\
\hline
\end{tabular}


In this work, the EPWM blocks are configured as operating in CU mode based on sawtooth carrier waveform. The equation to set up CU mode of sawtooth carrier waveform generated from EPWM output blocks is given in (14).

$T_{B P R D}=\frac{f_{S Y S C L K}}{f_{S W}}-1$

where $f_{S Y S C L K}$ is the maximum clock frequency of EZDSP
F28335 microcontroller which is configured to $150 \mathrm{MHz}$ (i.e., by default) as designated in the CPU clock and $f_{s w}$ is the switching frequency of gate signals.

The timer period TBPRD in (14) is calculated to be 3749 for $\mathrm{CU}$ mode to generate the pulse trains with $f_{s w}=40 \mathrm{kHz}$ from the EZDSP F28335 microcontroller.The configuration of each EPWM SIMULINK block is set according to Table 3.

Table 3: Configuration parameters of EPWM module in SIIMULINK model to output gate signals

\begin{tabular}{|c|c|c|c|c|c|c|}
\hline \multicolumn{7}{|l|}{ Block parameters } \\
\hline \multicolumn{7}{|c|}{ Timer period, $T_{B P R D}=3749$} \\
\hline \multicolumn{7}{|c|}{ CMPA initial value $=3749 / 2$} \\
\hline \multicolumn{7}{|c|}{ Counting mode $=$ Count-up } \\
\hline \multirow{2}{*}{ EPWM Module } & \multicolumn{6}{|c|}{ Configuration parameters } \\
\hline & Zero & PRD & $\mathrm{CAU}$ & CAD & $\mathrm{CBU}$ & CBD \\
\hline $1 \mathrm{~A}=G_{l}$ & Set & Set & Clear & Do nothing & Do nothing & Do nothing \\
\hline $1 \mathrm{~B}=G_{2}$ & Clear & Clear & Do nothing & Do nothing & Set & Do nothing \\
\hline $2 \mathrm{~A}=G_{3}$ & Set & Set & Clear & Do nothing & Do nothing & Do nothing \\
\hline $2 \mathrm{~B}=G_{4}$ & Clear & Clear & Do nothing & Do nothing & Set & Do nothing \\
\hline $\begin{array}{l}3 \mathrm{~A} \text { and } 4 \mathrm{~A} \\
=V_{u}\end{array}$ & Do nothing & Clear & Set & Do nothing & Do nothing & Do nothing \\
\hline $\begin{array}{l}3 \mathrm{~B} \text { and } 4 \mathrm{~B} \\
=V_{n}\end{array}$ & Do nothing & Clear & Set & Do nothing & Do nothing & Do nothing \\
\hline
\end{tabular}

When compared with sawtooth carrier waveform operated in Count-up-down (CUD) mode, the novel design method for CB-PWM technique allows the shoot-through and non-shoot-through pulse trains to be merged as shown in Figure 7 resulting that each switching device of qZSI should only be switched ON and OFF once per carrier cycle.Hence, this reduces the switching power loss as well as enhancing the system inversion efficiency. The only drawback of the proposed method is that the qZSN might exhibit twice the amount of inductor current ripples. Nevertheless, the aforementioned issue can be mitigated by selecting larger size of inductor and/or operating the inverter with high switching frequency. In this experiment work, by employing the design method for CB-PWM technique which modelled with MATLAB/SIMULINK to program the EPWM blocks of EZDSP F28335 microcontroller, the qZSI is operating at the switching frequency of $40 \mathrm{kHz}$ to reduce the inductor current ripples with smaller size of inductors.

Figure 8 shows the experimental results of the pulse trains (see Figure 8(a) for $S_{1} S_{2}$ and Figure 8(b) for $S_{3} S_{4}$ ) switching at $f_{s w}=40 \mathrm{kHz}$. These results are measured from the isolated gate drive opto-couplers consisting of shoot-through and non-shoot-through states, which employed to drive the qZSI for boosting up the DC input voltage. The resultant waveforms generated from the single-phase qZSI using the proposed method with CB-PWM technique are presented in Figure 8(c). With the built-in controller of EZDSP F28335 microcontroller, the experimental result shows that qZSI has boosted up its DC input voltage of $6 \mathrm{~V}$ to the DC output reference voltage of $10 \mathrm{~V}$ and then inverted into $\mathrm{AC}$ output waveform.

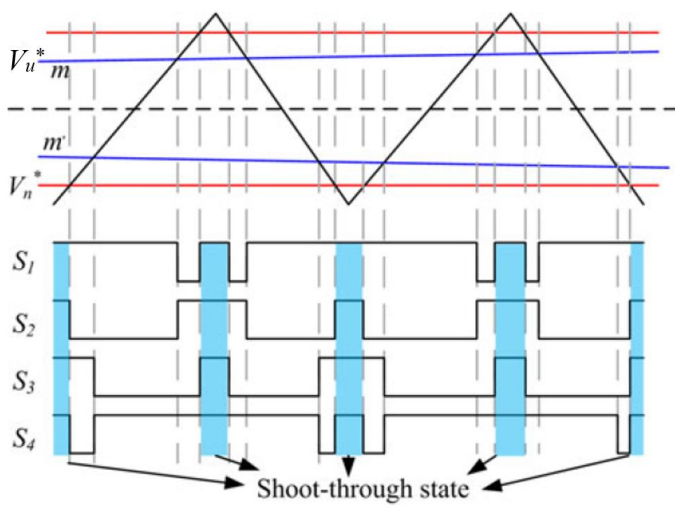

(a)

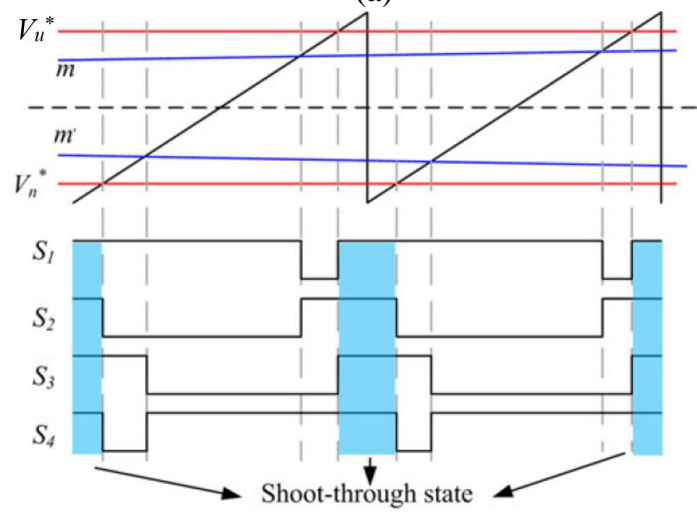

(b)

Figure 7: Modulation techniques for qZSI based on (a) CUD mode with triangular carrier waveform and (b) CU mode with sawtooth carrier waveform[25] 


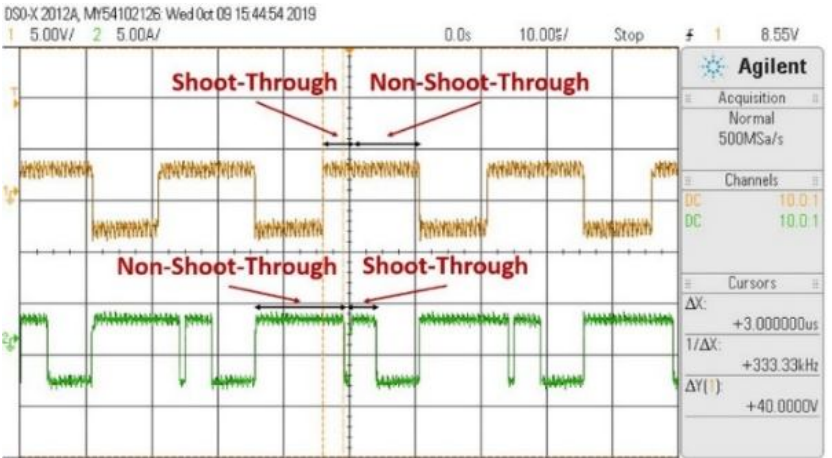

(a)

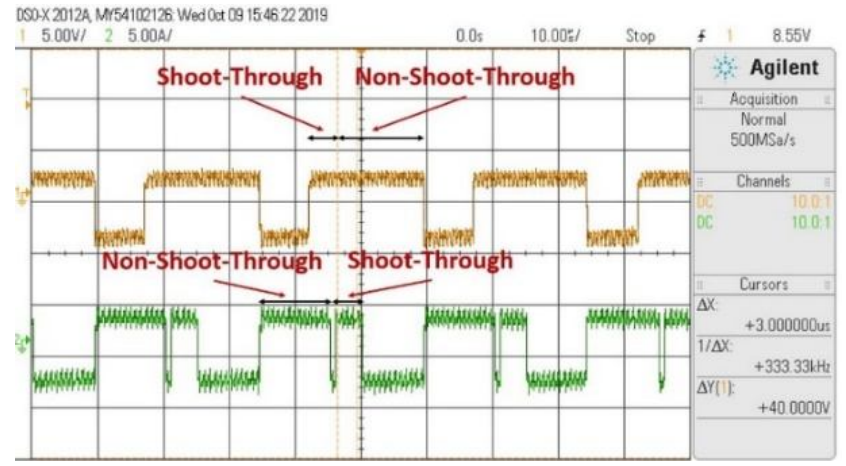

(b)

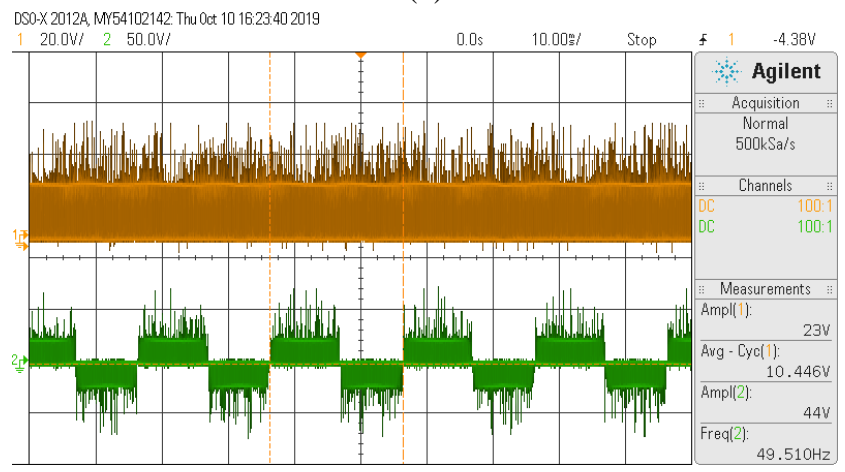

(c)

Figure 8: Experimental results for the measured switching pulse trains of (a) $S_{1}$ (top), $S_{2}$ (bottom), (b) $S_{3}$ (top), $S_{4}$ (bottom), (c) DC-link voltage $V_{d c}$ (top) and AC output voltage $V_{a c}$ (bottom)

\section{CONCLUSION}

This paper presented a new design method of CB-PWM technique which carried out with MATLAB/SIMULINK model to program the EZDSP F28335 microcontroller. This combo provides ease of hardware implementation for any power electronics with TI C2833x processor. From this work, it is proven that the EPWM blocks from MATLAB/SIMULINK enabled the EZDSP F28335 microcontroller to output very accurate and high switching frequency of pulse trains to the single-phase qZSI. In addition, the proposed CB-PWM technique operates in $\mathrm{CU}$ mode sawtooth carrier can reduce the switching power loss and improve the system inversion efficiency. Finally, all theoretical analysis, simulations, and experimental results are presented in this paper where all the aforementioned advantages have been listed out in this paper.

\section{REFERENCES}

1. K. H. Law, W. P. Q. Ng, and P. I. Au, Design, Modelling and Control Implementation of PV-MPPT Based DC-DC Converter for STATCOM, IOP Conference Series Materials Science and Engineering, vol. 495, iss. 1, pp. 012035, 2019.

2. C. P. Y. Lai, K. H. Law, K. H. Lim, Direct Fast Charging of Electric Vehicle Using Solar Power, in $20197^{\text {th }}$ International Conference on Smart Computing \& Communications (ICSCC), pp. 1-6, 2019.

3. Y. Rekha, I. W. Christopher, and V. Jamuna, Quasi-ZSI topology for renewable energy system: A review, in 2017 International Conference on Power and Embedded Drive Control (ICPEDC), pp. 333-337, 2017.

4. K. H. Law, W. N. Loh, and K. I. Wong, Mathematics Derivation and Simulation Modelling of Maximum Power Point Tracking based Controller for Quasi Z Source Inverter, in 2019 7th International Conference on Smart Computing \& Communications (ICSCC), pp. 1-5, 2019.

5. K. H. Law and M. S. A. Dahidah, New current control algorithm incorporating multilevel SHE-PWM approach for STATCOM operation under unbalanced condition, in 2014 IEEE 5th International Symposium on Power Electronics for Distributed Generation Systems (PEDG), pp. 1-7, 2014.

6. K. H. Law and M. S. A. Dahidah, DC-DC boost converter based MSHE-PWM cascaded multilevel inverter control for STATCOM systems, in 2014 International Power Electronics Conference (IPEC-Hiroshima 2014-ECCE ASIA), pp. 1283-1290, 2014.

7. K. H. Law, M. S. A. Dahidah, G. S. Konstantinou, and V. G. Agelidis, SHE-PWM cascaded multilevel converter with adjustable DC sources control for STATCOM applications, in Proceedings of The 7th International Power Electronics and Motion Control Conference, vol. 1, pp. 330-334, 2012.

8. L. K. Haw, M. Dahidah, and N. Mariun, Cascaded multilevel inverter based STATCOM with power factor correction feature, in 2011 IEEE Conference on Sustainable Utilization and Development in Engineering and Technology (STUDENT), pp. 1-7, 2011.

9. K. H. Law, W. P. Q. Ng, and W. K. Wong, Flyback cascaded multilevel inverter based SHE-PWM control for STATCOM applications,Internaltional Journal of Power Electronics and Drive System (IJPEDS), vol. 8, no.1, pp. 100-108, 2017.

10. A. Ayad and R. Kennel, A comparison of quasi-Z-source inverters and conventional two-stage inverters for $\mathbf{P V}$ applications, EPE journal, vol. 27, no. 2, pp. 43-59, 2017.

11. Y. Liu, B. Ge, H. Abu-Rub, and F. Z. Peng, Modelling and controller design of quasi-Z-source 
inverter with battery-based photovoltaic power system, IET Power Electronics, vol. 7, no. 7, pp. $1665-1674,2014$.

12. K. H. Law and W. P. Q. Ng, Dual Closed-Loop Scheme with Lead Compensator and Proportional Controller for Quasi Z-Source Inverter Based STATCOM, in 2018 IEEE 7th International Conference on Power and Energy (PECon), pp. 56-61, 2018.

13. K. H. Law, M. Dahidah, S. Y. Sim, W. P. Q. Ng, A. Masaoud, and A. Abu-Siada, An Effective Dual Closed-Loop Scheme Based on Lead Compensator and Proportional Controller for Quasi Z-Source Inverter, in TENCON 2018-2018 IEEE Region 10 Conference, pp. 20-25, 2018.

14. K. H. Law, Mathematics Modelling and Simulation of Batteries Charging Capability in Quasi Z Source Impedance Network, in 2019 7th International Conference on Smart Computing \& Communications (ICSCC), pp. 1-5, 2019.

15. Y. W. Sia and K. H. Law, Deep Analysis of Quasi Z Source Inverter for Batteries Charging and Discharging Capabilities Across All DC Capacitors' Terminals, in 2019 7th International Conference on Smart Computing \& Communications (ICSCC), pp. 1-5, 2019.

16. Y. Liu, H. Abu-Rub, and B. Ge, Z-SourceVQuasi-Z-Source inverters: derived networks, modulations, controls, and emerging applications to photovoltaic conversion, IEEE Industrial Electronics Magazine, vol. 8, no. 4, pp. 32-44, 2014.

17. Y. Liu, B. Ge, F. J. T. E. Ferreira, A. T. de Almeida, and $\mathrm{H}$. Abu-Rub, Modeling and SVPWM control of quasi-Z-source inverter, in 11th International Conference on Electrical Power Quality and Utilisation, pp. 1-7, 2011.

18. K. H. Law, W. P. Q. Ng, K. I. Wong, Active Harmonic Filtering Using Multilevel H-bridge Inverter Based STATCOM, IOP Conference Series: Materials Science and Engineering, vol. 495, iss. 1, pp. 012036.

19. D. Sun, B. Ge, F. Z. Peng, A. R. Haitham, D. Bi, and Y. Liu, A new grid-connected PV system based on cascaded $H$-bridge quasi-Z source inverter, in 2012 IEEE International Symposium on Industrial Electronics, pp. 951-956, 2012.

20. B. Ge, Y. Liu, H. Abu-Rub, and F. Z. Peng, State-of-charge balancing control for a battery-energy-stored quasi-Z-source cascaded-multilevel-inverter-based photovoltaic power system, IEEE Transactions on Industrial Electronics, vol. 65, no. 3, pp. 2268-2279, 2017.

21. J. O. S. Xuan, K. Y. S. Khan, L. K. Haw, W. N. P. Qin, and M. Dahidah, CCM and DCM analysis of quasi-z-source inverter, in 2017 IEEE Conference on Energy Conversion (CENCON), pp. 157-162, 2017.

22. S. K. Yong, K. H. Law, W. P. Q. Ng, and M. Dahidah, Lead compensator design for single-phase quasi z-source inverter,Journal of Telecommunication, Electronic and Computer Engineering, vol. 10, iss. 1-12, pp. 39-44, 2018.

23. A. Elrajoubi, S. S. Ang, and A. Abushaiba, TMS320F28335 DSP programming using MATLAB Simulink embedded coder: Techniques and advancements, in 2017 IEEE 18th Workshop on Control and Modeling for Power Electronics (COMPEL), pp. 1-7, 2017.

24. K. H/ Law,Modelling of Charging Control Scheme for QZSI with Battery Topology, Journal of Information Science and Engineering, vol. 36, iss. 5, pp. 967-979, 2020.

25. Y. Zhou, L. Liu, and H. Li, A high-performance photovoltaic module-integrated converter (MIC) based on cascaded quasi-Z-source inverters (qZSI) using eGaN FETs, IEEE Transactions on Power Electronics, vol. 28, no. 6, pp. 2727-2738, 2012. 